\title{
Axiomatic Design of Test Artifact for Laser Powder Bed Fusion Machine Capability Assessment
}

\author{
Alessandro Giorgetti, Filippo Ceccanti*, Paolo Citti, Andrea Ciappi, and Gabriele Arcidiacono
}

Guglielmo Marconi University, Department of Innovation and Information Engineering, Rome, Italy

\begin{abstract}
Additive Manufacturing is increasingly growing in importance in the manufacturing environment, allowing to realize very complex product designs. Identifying the real machine capability is becoming fundamental as additive manufacturing technologies are starting to substitute conventional manufacturing processes. This aspect holds particularly true in the case of Laser Powder Bed Fusion technology. In this case, the method to investigate and determine the actual machine capabilities still represents an open point. In this paper, we propose an analysis of a well-known test artifact from an Axiomatic Design standpoint; based on the results and the review of the Customer Needs, we develop an improved design which is able to ensure a robust analysis for a reliable machine performance check.
\end{abstract}

\section{Introduction}

Additive Manufacturing (AM) is a well-known production process, based on the build-up of material right where it is needed. The AM umbrella contains a lot of technologies, which allow the production of many different materials (polymers, ceramics, metals, composites, etc.). With a specific reference to metal, Laser Powder Bed Fusion (LPBF) technology is perhaps among the most important for the production of this kind of material.

LPBF process is based on the melting of a thin layer of metal powder by means of a highly focused laser; by repeating this process over and over, a metal component is built. Metals suitable for this technology are many, ranging from lightweight alloys (titanium or aluminium) to high-density alloys for the most various applications (e.g., stainless steels, nickel-based or cobalt-based superalloys, precious alloys, etc.).

LPBF is not necessarily an efficient solution for Rapid Prototyping only, but is starting to be used as a proper manufacturing technology. Regardless the implications rising from this paradigm transformation in a mechanical manufacturing environment, the use of LPBF as a mass production process rises many points to be answered. One of these is the product quality assurance.

Product quality is made of many and different aspects, such as material compliance with specifications, dimensional and geometrical accuracy, surface properties achievement, etc

Typically, a pre-defined qualification strategy based on statistic approach for component testing is used to ensure product quality.
Regardless of any component-related validation strategy, an overall qualification of the LPBF process is needed, which is the context in which this work has been developed. Process qualification is usually based on the performance assessment of every single productive system (i.e., LPBF machine). To check system performances, many authors [1] and LPBF suppliers propose the production of a sample representative of them, usually called test artifact. Most of the time test artifact design is characterized by a high level of complexity consisting in a great richness of geometric features, which can either be useful or disorienting depending on the case.

Besides, in most cases the capability assessment is considered as the main need; in our scenario (i.e. an additive production line), other aspects are fundamental too, such as results robustness and high efficiency in performance check.

As demonstrated by many authors working in wide ranges of environments and applications [2-16] Axiomatic Design (AD) provides a highly-structured decision-making process for the design phase of a product/process, especially when many and different needs shall be considered simultaneously [17-18].

Since this approach proved to be effective in driving the design process towards the best solutions with respect to the desired goals, this technique has been applied for the redesign of test artifact for LPBF technology performance check.

Therefore, the purpose of this work is to analyse a well-known test artifact from an AD perspective, in order to determine its performance concerning the application taken into account.

\footnotetext{
Corresponding author: f.ceccanti@unimarconi.it
} 
Basing on results retrieved by this analysis and on a Customer Needs (CNs) review, a new design is proposed. The new design is obtained thanks to the $\mathrm{AD}$ approach, and is specific for LPBF system periodic performance check.

In this work the methodological approach used to reach the final design is presented; details about the new design performances are presented in a different work [19].

\section{State of the Art analysis}

Among various test artifact proposed for the machine capability assessment of an additive manufacturing system, one of the most relevant is the one proposed by NIST [20].

This artifact (the design of which is observable in Fig. 1) allows the assessment of any aspects related with the Additive Manufacturing process, but it is a general sample specifically designed for the comparison between different AM systems (regardless any specific technology).

Briefly, this specimen is composed of many features, such as central cylinders, pins, ramp, staircases, holes, lateral features, line features, massive material, top surface, etc.

As observable from the pictures, all the features are grouped in a single specimen, which has lateral dimensions of $100 \times 100 \mathrm{~mm}^{2}$. Typically, the specimen shall be realized in the centre of the building platform and shall be geometrically inspected whilst still attached to it.

Taking this design as a reference, we have carried out an analysis from an AD standpoint to evaluate the design likeliness given our purposes. From the analysis, we identified some criticalities related to the use of this design as an artifact for LPBF systems performance check.

The analysis was based on the interpretation of the CNs from NIST standpoint.

Therefore, the inputs behind the NIST test artifact design are:

- Globally assess machine capabilities through the realization of a test artifact (regardless of the technology used);
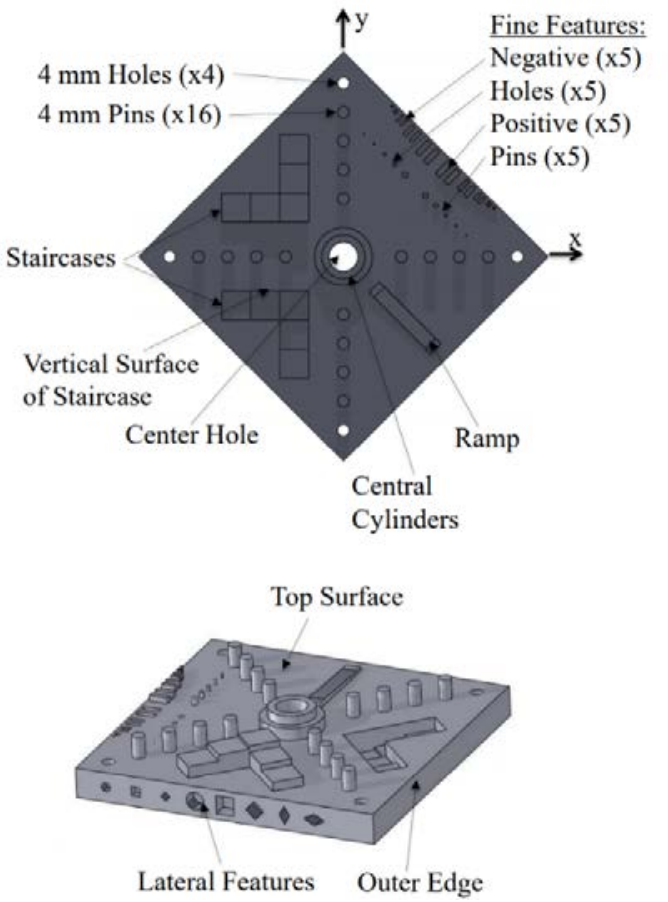

Fig. 1. NIST Test Artifact Description.

- Perform the assessment by analysing as many features as possible, to get the maximum amount of information available for each system inspected;

- Design a test artifact which is rich in features but also as most feasible with most commercial system as possible (without any reference to a specific technology).

Based on these ideal CNs by NIST, the following Functional Requirements (FRs) were identified:

- $\mathrm{FR}_{1}$ check machine performance;

- $\quad \mathrm{FR}_{1.1}$ acquire as many data as possible;

- FR $_{1.2}$ compare different technologies;

Starting from these high-level FRs, which satisfy the Independence Axiom, we identified the corresponding Design Parameters (DPs) and went through the definition of the whole FRs-DPs tree, reported in Fig. 2. Table. 1 represents the meaning of each diagram cell.

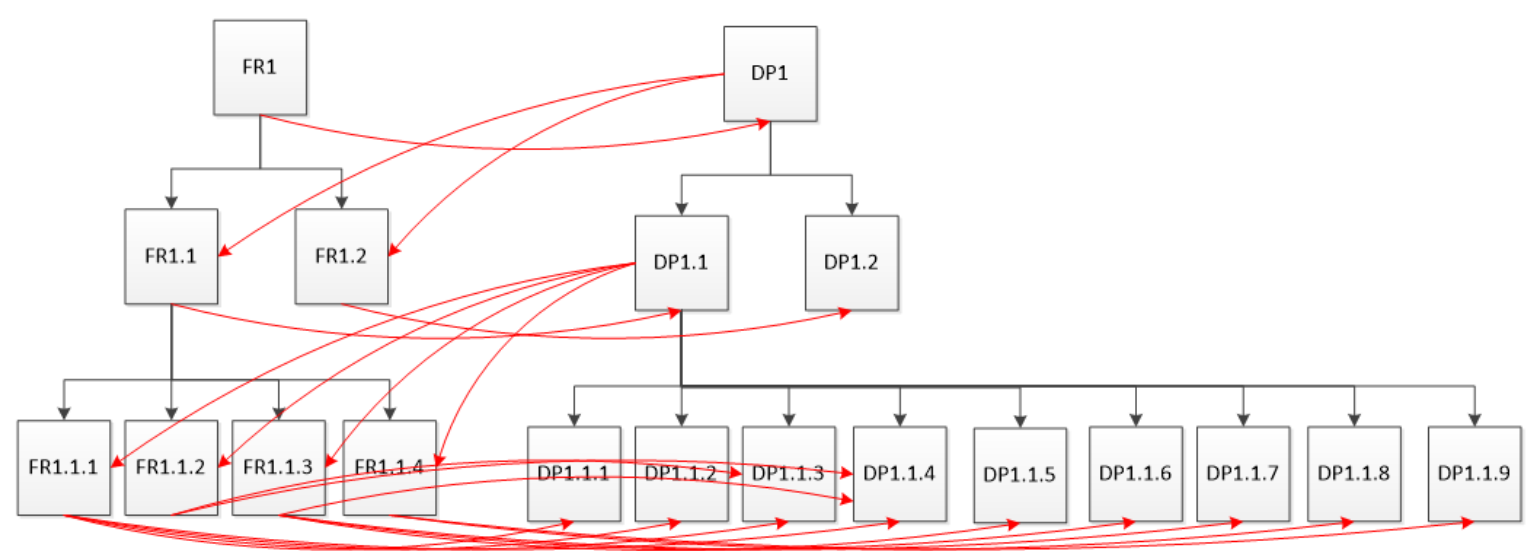

Fig. 2. NIST FRs-DPs Tree with the Zig-Zagging. 
Table 1. FRs and DPs meaning.

\begin{tabular}{|l|l|}
\hline \multicolumn{2}{|c|}{ FR } \\
\hline 1 & Machine Performance Check \\
\hline 1.1 & Acquire as Many Data as Possible \\
\hline 1.1 .1 & Measure Precision \\
\hline 1.1 .2 & Measure Shrinkage \\
\hline 1.1 .3 & Assess Capability \\
\hline 1.1 .4 & Measure Roughness \\
\hline 1.2 & Compare Different Technologies \\
\hline & \\
\hline 1 & Danufacture Test Artefact \\
\hline 1.1 & Realize Complex Geometries with Many Features \\
\hline 1.1 .1 & Pins \\
\hline 1.1 .2 & Central Cylinders \\
\hline 1.1 .3 & Holes \\
\hline 1.1 .4 & Massive Material \\
\hline 1.1 .5 & Lateral Features \\
\hline 1.1 .6 & Fine Features \\
\hline 1.1 .7 & Staircase Features \\
\hline 1.1 .8 & Ramp Features \\
\hline 1.1 .9 & Flat Top Plane \\
\hline 1.2 & Satisfy General AM Manufacturability Constraints \\
\hline
\end{tabular}

As observable from the diagram, the design appears non-optimal from an AD standpoint. The relationship between FRs and DPs is well represented in Table. 2. In particular, it is evident how:

- Matrix is neither diagonal nor square;

- The use of certain features (such as massive material) physically introduces a superposition of effects.

This last point represents a very critical issue to be solved because it potentially makes the inspection of the other features at least affected by an external noise, which is not representative of the actual process. In addition, the influence of this effect is very important when considering heavy alloys, such as nickel-based or cobalt-based. This is relevant since many LPBF applications are based on these kinds of material.

In summary, the use of this specimen design for the LPBF system performance check in an AM production line is non-optimal.

Our works takes place starting from these preliminary considerations.

\section{CNs Review}

Basing on the AD analysis of the reference artifact, it appears evident how the supposed CNs are not specific for the application that we are analysing.

A CNs review was carried out to identify the actual requirements from the customer:

- $\mathrm{CN}_{1}$ Assess machine capabilities;

- $\mathrm{CN}_{2}$ Performance check shall be performed fast;

- $\mathrm{CN}_{3}$ Performance check shall be cheap;

- $\mathrm{CN}_{4}$ Results coming from the check shall be robust and reliable;

- $\mathrm{CN}_{5}$ Performance check shall be the same among machine with homogeneous characteristics;

- $\mathrm{CN}_{6}$ Performance check shall be safe for that who carries it out;

It is important to highlight that these $\mathrm{CNs}$ are significantly different one another, with the exception of $\mathrm{CN}_{1}$.

The overall purpose of the activity is still to assess machine performances. However, while in the first case there is no reference to anything specific and/or defined, in the second scenario LPBF systems are similar, making other factors (such as machine time-occupancy and cost check) growing in importance.

Table 2. NIST FRs-DPs Matrix.

\begin{tabular}{|c|c|c|c|c|c|c|c|c|c|c|c|c|c|}
\hline \multirow{2}{*}{\multicolumn{2}{|c|}{ 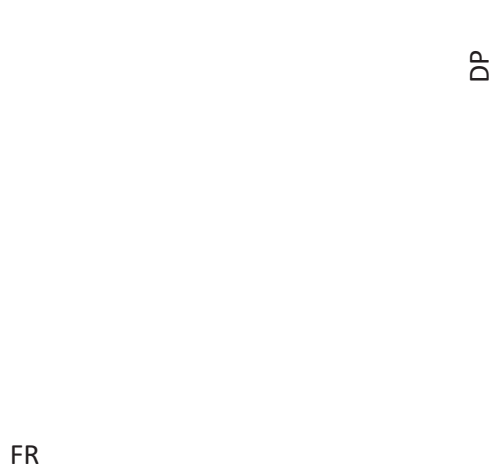 }} & -1 & تיב- & $\begin{array}{l}\stackrel{-}{\mathrm{H}} \\
\stackrel{\mathrm{H}}{-}\end{array}$ & $\begin{array}{c}n \\
\stackrel{H}{-} \\
-i\end{array}$ & $\begin{array}{l}m \\
\stackrel{m}{-} \\
r \\
r\end{array}$ & $\begin{array}{l} \\
\stackrel{H}{-} \\
\stackrel{-}{-}\end{array}$ & 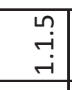 & \begin{tabular}{l|} 
\\
+ \\
- \\
$-i$ \\
\end{tabular} & $\begin{array}{l}r \\
\stackrel{-}{r} \\
-i\end{array}$ & $\begin{array}{l}\infty \\
\\
\\
\end{array}$ & $\begin{array}{l}\text { O् } \\
\text { - } \\
\text { - }\end{array}$ & $\underset{\sim}{\sim}$ \\
\hline & & 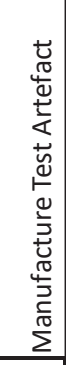 & 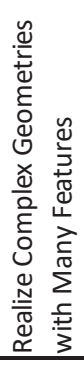 & $\stackrel{\varrho}{a}$ & 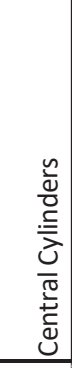 & $\begin{array}{l}\frac{\tilde{\varpi}}{0} \\
\text { 오 }\end{array}$ & 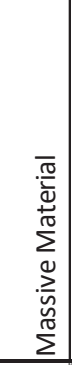 & 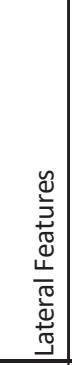 & 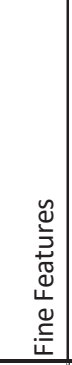 & 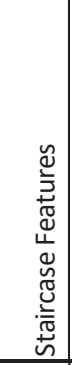 & 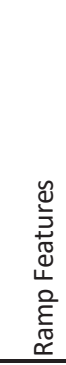 & $\begin{array}{l}0 \\
\frac{0}{\pi} \\
\frac{\pi}{2} \\
\circ \\
\circ \\
\circ \\
\frac{\pi}{0} \\
\frac{\pi}{4}\end{array}$ & 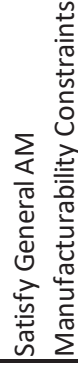 \\
\hline 1 & Machine Performance Check & $\mathbf{x}$ & & & & & & & & & & & \\
\hline 1.1 & Acquire as Many Data as Possible & & $\mathbf{x}$ & & & & & & & & & & \\
\hline 1.1 .1 & Measure Precision & & & $\mathrm{x}$ & $\mathrm{X}$ & $\mathrm{x}$ & $\mathrm{X}$ & & & & & & \\
\hline 1.1 .2 & Measure Shrinkage & & & & & $x$ & $\mathrm{x}$ & & & & & & \\
\hline 1.1 .3 & Assess Capability & & & & & & $\mathrm{x}$ & $\mathbf{x}$ & $\mathbf{x}$ & $\mathrm{x}$ & & & \\
\hline 1.1 .4 & Measure Roughness & & & & & & & & & & $\mathbf{x}$ & $\mathbf{x}$ & \\
\hline 1.2 & Compare Different Technologies & & & & & & & & & & & & $\mathbf{x}$ \\
\hline
\end{tabular}




\subsection{FRs Definition and AD Re-Design}

Based on the reviewed CNs listed before, a new set of FRs has been defined.

Starting from their definition, we made the following assumptions [21]:

- $\mathrm{CN}_{6}$ shall not be considered as an FR; instead, it shall be considered as a non-Functional Requirement (nFR);

- $\mathrm{CN}_{2}$ and $\mathrm{CN}_{3}$ lead to FRs that will not satisfy the Independence Axiom; the reason for this is represented by their very nature. Because of this, speed will be considered as an actual FR, whereas the cost will be considered as a Selection Criteria (SC);

- $\mathrm{CN}_{5}$ represents a constraint rather than an actual FR; therefore, it will be considered as such.

In addition, given the exponential technological progress that is characterizing the LPBF technology, another constraint that shall be taken into account is the physical system architecture: for the purpose of this work, we considered single-laser systems only, considering that they currently represent the most widespread industrial application of this technology.

With this in mind, the highest-level $\mathrm{CN}$ is still represented by $\mathrm{CN}_{1}$, it being the machine capability assessment for a periodic performance check.

Accordingly, the first design choice (that is $\mathrm{DP}_{1}$ ) consists in the adoption of the same inspection strategy (or rather, the realization of a test artifact).

This DP comes from the desire to continue checking the machine performance through the realization of a test artifact, which is representative of the actual machine conditions.

Once this first DP has been defined, based on classical AD Zig-Zagging process, lower-level FRs were defined:

- $\quad \mathrm{FR}_{1.1}$ Produce the test artifact fast;

- $\mathrm{FR}_{1.2}$ Analyse the test artifact fast;

- $\mathrm{FR}_{1.3}$ Deliver robust results;

These FRs come from the CNs analysis and their interpretation as shown above.

At this stage, we completed the definition of lowerlevel DPs and FRs through the Zig-Zagging process.

The resulting FRs-DPs tree is represented in Fig. 3, whereas the meaning of each cell is reported in Table. 3.

Table 3. FRs and DPs meaning.

\begin{tabular}{|l|l|}
\hline \multicolumn{2}{|c|}{ FR } \\
\hline 1 & Check Machine Performance \\
\hline 1.1 & Produce the Test Artefact Fast \\
\hline 1.1 .1 & produce job fast \\
\hline 1.1 .2 & avoid repetition/ interruption \\
\hline 1.2 & Analyse the Test Artefact Fast \\
\hline 1.2 .1 & use only one measuring system \\
\hline 1.2 .2 & use available machines \\
\hline 1.3 & Deliver Robust Result \\
\hline 1.3 .1 & Choose only Meaningful Parameters \\
\hline 1.3 .1 .1 & optimize specimen design to get selected parameters \\
\hline 1.3 .2 & avoid superposition of effect \\
\hline 1.3 .3 & avoid thermal effects / shrinkages \\
\hline 1.3 .4 & analyse the whole working space \\
\hline & \\
\hline 1 & Produce Test Artefact \\
\hline 1.1 & Use the Machine for a Small Time \\
\hline 1.1 .1 & produce small features \\
\hline 1.1 .2 & produce simple geometries \\
\hline 1.2 & Use a Simple and Significant Analysis \\
\hline 1.2 .1 & measure via CMM \\
\hline 1.2 .2 & ensure dedicated machine for performance check \\
\hline 1.3 & Design Specimen and Inspection Plan for Robustness \\
\hline 1.3 .1 & Measure BO and Laser Positioning Only \\
\hline 1.3 .1 .1 & print only pin in a specific pattern \\
\hline 1.3 .2 & no massive material below main features \\
\hline 1.3 .3 & features shall have thickness less than $5 \mathrm{~mm}$ \\
\hline 1.3 .4 & spread fweatures above the whole Building Paltform \\
\hline
\end{tabular}

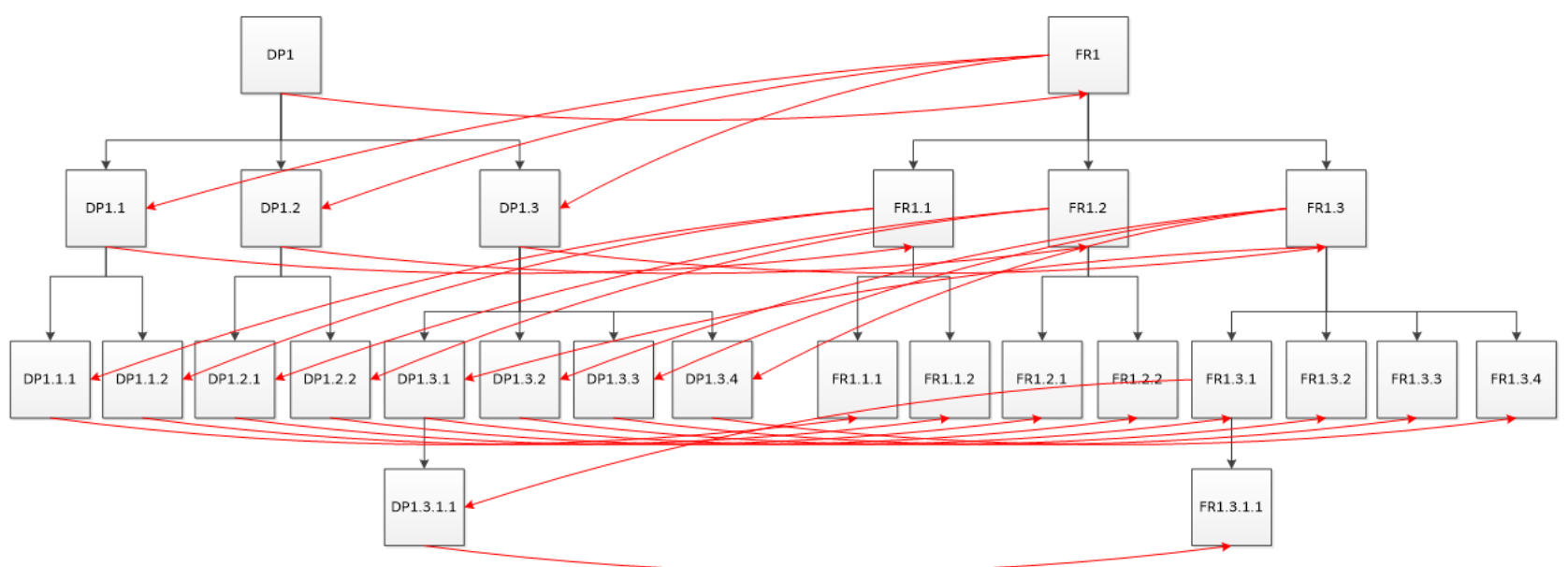

Fig. 3. Re-Design FR-DPs Tree wit Zig-Zagging. 
Table 4. Re-Design FRs-DPs Matrix.

\begin{tabular}{|c|c|c|c|c|c|c|c|c|c|c|c|c|c|c|}
\hline$F R$ & & $\frac{0}{2}$ & 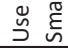 & $\frac{0}{2}$ & 을 & 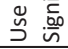 & $\stackrel{\mathbb{2}}{\mathrm{E}}$ & ज़ & 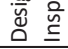 & $\sum^{\pi}$ & . & \begin{tabular}{ll}
5 & 0 \\
0 & 0 \\
\hdashline & 0
\end{tabular} & 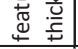 & 产 $\frac{0}{3}$ \\
\hline 1 & Check Machine Performance & $\mathbf{x}$ & & & & & & & & & & & & \\
\hline 1.1 & Produce the Test Artefact Fast & & $\mathbf{x}$ & & & & & & & & & & & \\
\hline 1.1.1 & produce job fast & & & $\mathbf{x}$ & & & & & & & & & & \\
\hline 1.1 .2 & avoid repetition/ interruption & & & & $\mathbf{x}$ & & & & & & & & & \\
\hline 1.2 & Analyse the Test Artefact Fast & & & & & $\mathbf{x}$ & & & & & & & & \\
\hline 1.2 .1 & use only one measuring system & & & & & & $\mathbf{X}$ & & & & & & & \\
\hline 1.2 .2 & use available machines & & & & & & & $\mathbf{x}$ & & & & & & \\
\hline 1.3 & Deliver Robust Result & & & & & & & & $\mathbf{x}$ & & & & & \\
\hline 1.3 .1 & Choose only Meaningful Parameters & & & & & & & & & $\mathbf{x}$ & & & & \\
\hline 1.3.1.1 & optimize specimen design to get selected parameters & & & & & & & & & & $\mathbf{x}$ & & & \\
\hline 1.3 .2 & avoid superposition of effect & & & & & & & & & & & $\mathbf{x}$ & & \\
\hline 1.3 .3 & avoid thermal effects / shrinkages & & & & & & & & & & & & $\mathbf{x}$ & \\
\hline 1.3.4 & analyse the whole working space & & & & & & & & & & & & & $\mathbf{X}$ \\
\hline
\end{tabular}

The presented analysis shows clearly how the AD approach for the test artifact re-design has led towards a better result in terms of robustness and independence of measurements that are potentially retrievable from specimen analysis.

The inspection method is also well defined, consisting in the measure of features diameter and position.

These considerations are well identifiable in Table 4.

\section{Resulting Design}

The resulting design, which has been obtained through the application of the AD process, is represented in Figure 4.

One of the most important aspects of the new design is that the actual test artifact is not the whole model represented in the picture. It actuallyconsists in the pins only, which are printed above the building platform (i.e. the grey parallelepiped with four counterbores to allow to bolt it into the machine).

Therefore, there is no material printed below the main features. The following section will go through the reason behind it in better detail.

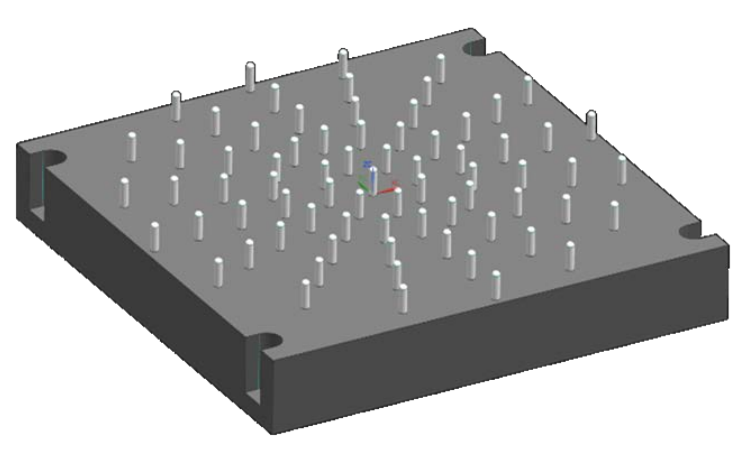

Fig. 4. Re-Designed Test Artifact CAD Model.

\section{Discussions and Reflections}

Design provided by the application of the AD strategy to this problem brought a complete redefinition of the overall approach, as well as the intended optimization of an existing procedure.

The first relevant consideration regards the actual definition of the customer need: the NIST design is appropriate for comparing different systems and/or technologies, whereas in our case needs are different, given its higher specificity. Thanks to $\mathrm{AD}$, we have been forced to analyse the actual needs; based on them, the design process has been driven by the identified needs, improving the chance to get the best design possible with respect to the specific application requirements.

The optimization of the test artifact design brought significant advantages: the artifact building time has been reduced by $4 / 5$ compared to the original one, while the inspection time has been dramatically reduced thanks to the single analysis required.

The trade-off reached with the new design obviously has to take into account a loss of information with respect to the reference design. This loss, however, does not affect the test artifact effectiveness, since the meaningful features have not been modified.

Anylaser power modification that occurs due to an internal fluctuation of the LPBF system is automatically detected by the machine, as well as other major failures.

Realization of pins is important because it allows checking the dimensional performance of LPBF systems.

The need of the LPBF production line owner is to have the same dimensional performances among all the systems available. The underlying assumption is that LPBF is characterized by poor accuracy performances, mainly due to its physical nature: the powder melting process has the unavoidable drawback consisting in an unmelted powder mantle, which does not allow to reach 
accuracy lower than the powder grain size itself (which typically ranges from $5 \mu \mathrm{m}$ to $65 \mu \mathrm{m}$ ).

On top of this, two additional factors affect the nominal dimension of a component produced via LPBF:

- Material shrinkages during the solidification, which create stress inside of it;

- Beam offset compensation.

The first effect can be simulated and compensated or directly compensated via a trial-and-error process, while the second can be manually adjusted. Once the CAD model is compensated, it is crucial to have machines with the same dimensional accuracy.

Based on the fact that the beam offset compensation varies between different systems, it is fundamental to correct it on each machine to have the same dimensional performances among them. These is the reason why printing pin features should be preferred.

The other important factor to be controlled is whether the system can point the laser where it is required (i.e., the machine precision in laser pointing). Due to the highfocus nature of the laser, a direct measure is difficult and expensive.

An indirect method consists in the measurement of the position of pin axes; in this way, it is possible to assess machine precision indirectly.

The resolution of this measurement system is not so high, yet is accurate enough if compared with the general LPBF capability in terms of accuracy.

Hence, by analysing the pins alone, it is possible to check if an LPBF system works fine or not; this is also because systems have a monitoring diagnostic that allows automatic detection of major issue (i.e., laser source malfunctioning, excessive oxygen concentration, etc.). Pins dimensioning, even considering what has been already said, shall be as such:

- Small enough to make shrinkage effects negligible in their diameter;

- Big enough to avoid to be bent by the re-coater during their building.

For their inspection, a Coordinate Measuring Machine (CMM) has been chosen and used because of its high repeteability once the measuring program is done (unlike other systems such as light scanning or laser scanning). With this solution, measuring time is dramatically reduced if compared to other analysis methods.

It is important to underline how this design reduces the superposition of effects as much as possible, leaving most essential features of the system independent; this implies that, when measuring these, there is not any additional effect due to other variables.

\section{Conclusions}

Many times, especially in the innovative fields of the industrial environment, the adoption of structured approaches are not adequately considered or applied.

In process engineering, many procedures have been defined based on knowledge and experience. This approach, in addition with the knowledge turnover that characterizes large and complex organizations, typically brings to non-optimal solutions. The reason for this, many times, shall be ascribed to a lack of structure since the beginning of the procedure design.

Working in this environment, the procedure re-design based on AD technique has been considered and carried out to re-define what is actually needed and what can be ignored for the sake of the specific case.

Once the real needs have been identified, AD approach has been rigorously followed to get a result which is defined based on a structured procedure rather than just experience and knowledge.

The designed artifact has been already implemented and tested. Results retrieved by its analysis have been compared with the reference design, and they turned out to be aligned with expectations (very reliable results for a clear and robust performance check). An in deep technical analysis about this comparison is presented in another work made by the authors.

As already mentioned, the usage of $\mathrm{AD}$ technique for the re-definition and re-design of a specimen for a specific problem brought in light the potential of this technique. Results achieved are beyond the expectations, because we achieved an improvement on every main aspect: time, cost and outcome reliability.

It is important to underline that these results do not depend only on the AD approach application: they have been obtained thanks to the integration of experience and knowledge with the AD rules.

As a next step, after the physical validation of the design (already carried out, as said), the re-design of the whole LPBF system inspection plan shall be carried out from an $\mathrm{AD}$ standpoint.

\section{References}

1. L. Rebaioli \& I. Fassi, A review on benchmark artifacts for evaluating the geometrical performance of additive manufacturing processes. Int $\mathrm{J}$ Adv Manuf Technol 5-8 2571-2598 (2017) DOI:10.1007/s00170-017-0570-0

2. A.M.G. Coelho \& A.J.F. Mourão, Axiomatic design as support for decision-making in a design for manufacturing context: A case study. Int $\mathrm{J}$ of Prod Economics, $\quad \mathbf{1 - 2} \quad 81-89 \quad$ (2007) DOI:10.1016/j.ijpe.2006.11.002

3. C.A. Brown, Axiomatic Design Applied to a Practical Example of the Integrity of Shaft Surfaces for Rotating Lip Seals. Procedia Engineering 19 5359 (2011) DOI:10.1016/j.proeng.2011.11.079

4. G Arcidiacono, D.T. Matt, E. Rauch, Axiomatic Design of a Framework for the Comprehensive 
Optimization of Patient Flows in Hospitals", J Healthc Eng (2017) DOI:10.1155/2017/2309265

5. G. Arcidiacono, M. Molon, S. Nuzzi, P. Placidoli, Improving Reliability of a fire-fighting pump set with Axiomatic Design, MATEC Web of Conferences, Vol. 127, article id. 01014 MATEC Web Conf 127 (2017) DOI:10.1051/matecconf/201712701014

6. A. Giorgetti, A. Girgenti, P. Citti, M. Delogu, A novel approach for axiomatic-based design for the environment. In: Farid A., Suh N. (eds) Axiomatic Design in Large Systems, 131-148 (2016) DOI:10.1007/978-3-319-32388-6_5

7. G.Ó. Sölvason \& J.T. Foley, Low-cost spectrometer for icelandic chemistry education. Procedia CIRP, 34 156-161 (2015) DOI:10.1016/j.procir.2015.07.072

8. J.T. Foley \& S. Harardóttir, Creative axiomatic design. Procedia CIRP 50 240-245 (2016) DOI:10.1016/j.procir.2016.04.116

9. C. Monti, A. Giorgetti, A. Girgenti, An Axiomatic Design Approach for a Motorcycle Steering Damper. Procedia CIRP, 34, 150-155 (2015) DOI:10.1016/j.procir.2015.07.081

10. Y. Wang, A. Liu, Student's Axiomatic Design Application Example of Battery Thermal Controller for High Altitude Balloon. MATEC Web of Conference 223,

(2018) DOI:10.1051/matecconf/201822301017

11. K. Iino, A. Arruti \& M. Nakao, Axiomatic Design Aspect of a Braking System Redesign. MATEC Web of Conferences, $\quad \mathbf{1 2 7}$ DOI: $10.1051 /$ matecconf $/ 201712701003$

(2017)

12. M.C. Bahadir, S.I. Satoglu, A novel robot arm selection methodology based on axiomatic design principles. The International Journal of Advanced Manufacturing Technology 71(9-12) 2043-2057 (2014) DOI:10.1007/s00170-014-5620-2

13. I.C. Bang \& G. Heo, An axiomatic design approach in development of nanofluid coolants. Applied
Thermal Engineering 29(1) 75-90

(2009) DOI:10.1016/j.applthermaleng.2008.02.004

14. A. Girgenti, A. Giorgetti, M. Anselmi, A. Scatena, Improvement of the Test Equipment for a Stress Corrosion Lab through the Axiomatic Design, $\begin{array}{lllll}\text { Procedia CIRP } & 34 & 162-167 & \text { (2015) }\end{array}$ DOI:10.1016/j.procir.2015.07.067

15. A. Girgenti, A. Giorgetti, P. Citti, M. Romanelli, Development of a Custom Software for Processing the Stress Corrosion Experimental Data through Axiomatic Design. Procedia CIRP 34 250-255 (2015) DOI:10.1016/j.procir.2015.07.064

16. G. Arcidiacono, C. Brown, L. Bucciarelli, F. Melosi, Axiomatic Design of Production Systems for Performance Improvement: A Project Identification and Prioritization Model, In: Farid A., Suh N. (eds) Axiomatic Design in Large Systems 251-262 (2016) DOI:10.1007/978-3-319-32388-6_10

17. N.P. Suh. Axiomatic design: Advances and applications. Oxford University Press, New York (2001)

18. N.P. Suh, Complexity: Theory and Applications, Ed. Oxford University Press (2005).

19. F. Ceccanti, A. Giorgetti, S. Kemble, P. Citti. Machine Capability Monitoring Through Test Artifacts Analysis, The Intern J of Adv Manuf Tech, forthcoming (2019)

20. S. Moylan, J. Slotwinski, A. Cooke, K. Jurrens, M.A. Donmez, An Additive Manufacturing Test Artifact. J of Res of the Nat Inst of Standards and Tech, 119 (2014) DOI:10.6028/jres.119.017

21. M.K. Thompson, A Classification of Procedural Errors in the Definition of Functional Requirements in Axiomatic Design Theory. Proceedings of the 7th International Conference on Axiomatic Design (ICAD'13), Worcester, MA (2013) 